\title{
The Effect of Surgical Technique, Age and Trisomy 21 on Early Outcome of Surgical Management of Complete Atrioventricular Canal Defect
}

\section{Sherief Azzab}

Ain Shams University Faculty of Medicine

\section{Ahmed Samy}

Ain Shams University Faculty of Medicine

\section{Hamdy Singab}

Ain Shams University Faculty of Medicine

\section{Mohamed Zeinah}

Liverpool Heart and Chest Hospital

\section{Gledisa Musollari}

Imperial College Faculty of Medicine - South Kensington Campus: Imperial College London Faculty of Medicine

\section{Ariana Axiaq}

Queen's University Belfast School of Medicine Dentistry and Biomedical Sciences

Amer Harky ( $\square$ aaharky@gmail.com )

Liverpool Heart and Chest Hospital

\section{Ahmed Tarek}

Ain Shams University Faculty of Medicine

Mohamed EL Ghanam

Ain Shams University Faculty of Medicine

\section{Research Article}

Keywords: Complete Atrioventricular Canal, Down syndrome, Double patch technique, Modified Single patch, Posterior annuloplasty

Posted Date: April 30th, 2021

DOI: https://doi.org/10.21203/rs.3.rs-450513/v1

License: (c) (i) This work is licensed under a Creative Commons Attribution 4.0 International License. Read Full License 


\section{Abstract}

Background: The optimal timing, surgical technique and the influence of Trisomy 21 on outcome of surgical repair of Complete Atrio-Ventricular Canal Defect (CAVC) remain uncertain. We reviewed our experience in repair of CAVC to identify the influence of these factors on operative outcome.

Methods: A prospective study included 70 patients who underwent repair of CAVC at our institute between July 2016 to October 2019. Primary endpoint was mortality and secondary endpoint was degree of left atrio-ventricular valve (LAVV) regurgitation.

Results: No significant difference noted between patients operated on, at the first 6 months of age versus later, regarding mortality or LAVV regurgitation. Surgical repair by modified single patch technique showed significant reduction in bypass time $(71.13 \pm 13.507 \mathrm{~min}$ vs $99.19 \pm 27.092 \mathrm{~min}, \mathrm{P}$ value $=0.001)$. Comparison to closure of cleft only, posterior annuloplasty used for repair of LAVV resulted in significant reduction in the occurrence of post-operative valve regurgitation during the early period (LAVV $2+43 \%$ vs $7 \%, P$ value $=0.03$ ) and at 6 months of follow up (LAVV $2+35.4 \%$ vs $0 \%, P$ value $=0.01$ ) respectively.

Conclusion: Early intervention, in the first 6 months in patients with CAVC by surgical repair gives comparable acceptable results to later repair; Trisomy 21 was not found to be a risk factor for early intervention. Repair of common AV valve by cleft closure with posterior LAVV annuloplasty showed better results with significant decrease in postoperative LAVV regurgitation and early mortality in comparison to closure of cleft only.

\section{Summary}

\section{What is Known:}

- Trisomy 21 is a known risk factor for developing atrioventricular septal defect

- Several techniques exist for repair of such pathology

\section{What is New:}

- No correlation between trisomy 21 and outcomes

- Early repair should be offered for patients with atrioventricular septal defects

\section{Introduction}

Complete Atrio-Ventricular Canal Defect (CAVC) is a complex cardiac malformation in which there is a variable deficiency of the atrioventricular (AV) junction in the developing heart(1). This anomaly is characterized by the atrial, ventricular and atrioventricular septa, and the left (LAVV) and right (RAVV) atrioventricular valves $(\mathrm{AVV})(2)$. 
During the 1970 s and early 1980s, surgeons advocated palliation with pulmonary artery banding to delay surgical repair beyond infancy, aiming to prevent more elevation of pulmonary artery pressure (3). On the other hand, as operative techniques and postoperative care improved and cardiopulmonary bypass in infants became safer $(4,5)$, most cardiac centres abandoned this practice and opted for elective repair before 6 months of age in asymptomatic infants with $\operatorname{CAVC}(6,7,8,9)$. Delay beyond this age has recently been shown to be an incremental risk factor for death and reoperation for LAAV regurgitation ( 6 , $7,8,9)$. Infants with failure to thrive and with symptoms of heart failure requiring multiple medications should undergo surgery as soon as possible to permit normal growth and development (10).

Two standard methods for repair of CAVC defect are used: first, is the single-patch technique, where the same patch is used for closure of the atrial septal defect (ASD) and ventricular septal defect (VSD), the AVV leaflets are re-suspended onto this single patch, with a need for leaflet division. This allows patch placement for Rastelli type $C$, which by definition has a common superior leaflet $(7,11,12)$. Second, is the double-patch technique; 2 separate patches are used, one for closure of the VSD and the other for closure of the ASD; the AVV leaflets are typically not divided $(13,14,15)$. In the mid-1990s, the modified singlepatch technique was introduced, which is characterized by the obliteration of interventricular communication by direct closure of the bridging leaflet and septal crest and then closure of ASD using single pericardial patch (16).

\section{AIM OF THE WORK}

To evaluate the early results of surgical total repair of Complete Atrioventricular Canal Defect (CAVC) in relation to three important risk factors which are, early repair in the first 6 months of life versus later repair, surgical technique (modified single patch versus double patch technique and adding posterior annuloplasty to the repair of left atrioventricular valve versus not) and Trisomy 21 versus Non-Trisomy 21 patients.

\section{Patients And Methods}

A prospective study in which 70 patients with a CAVC underwent definitive surgical repair from July 2016 to October 2019 at Cardio-thorathic Surgery Department Paediatric Unit, Ain Shams University Hospitals. Follow-up was done for a duration of 6 months post-surgery through regular outpatient visits with recent echocardiography. The study was approved with waiver of consent by the Institutional Review Boards of the University of Ain-Shams.

All patients were operated on via an elective basis; age ranged between 2 months and 24 months, and cases included Trisomy 21 and Non-Trisomy 21 patients. The selection criteria excluded patients refusing to participate in the study, patients who underwent previous pulmonary artery banding, patients with an incomplete canal defect (partial atrioventricular canal defect), patents with unbalanced complete atrioventricular canal defect not suitable for biventricular repair, patients with cono-truncal complex anomalies (including tetralogy of Fallot, double-outlet right ventricle and pulmonary stenosis) and patients with a single ventricle. 
All patients had preoperative echocardiography and multi-slice CT chest to confirm diagnosis and exclude any associated complex anomalies. Surgical repair was performed through median sternotomy, using cardiopulmonary bypass and moderate hypothermia with antegrade cardioplegia to achieve diastolic arrest. This was followed by right atriotomy and performing the repair.

\section{Two techniques were used for repair as follows:}

The modified Single-patch technique (Australian technique), similar to that described by Nunn and colleagues (17), was used in 39 cases (55.7\%) and a two-patch technique was used for closure of septal defects in 31 cases (44.3\%). Gortex patches were used for the ventricular component and autologous pericardium for the atrial defect. In 40 patients $(57.1 \%)$ cleft was closed and posterior annuloplasty was added to the repair. Intraoperative testing for competency of the left AVV was done by injecting saline in the left ventricle.

Following completion of the repair, closure of right atriotomy and de-airing of the left side of the heart was performed through the aortic root, followed by weaning from cardiopulmonary bypass, routine haemostasis and closure in layers.

The following data were recorded; age, weight, Trisomy 21 or Non-Trisomy 21 patient, cross-clamp time, total bypass time, technique used for repair: whether double or modified single-patch and whether repair was performed with posterior valve annuloplasty or not, and patient rhythm both on going off bypass and on discharge from the operating theatre.

During ICU stay, measurements included postoperative ventilation duration, incidence of re-exploration for bleeding, total intensive care unit stay, incidence of arrhythmia and heart block.

Other operative complications were also recorded including superficial wound infection, mediastinitis, pleural collection, lung collapse, chest infection, early re-operation (within one month of surgery). Inhospital mortality was also recorded.

Postoperative echocardiography was performed to detect the presence and degree of mitral valve regurgitation, left ventricular dimensions, presence of pericardial collection, presence of left ventricular outflow tract (LVOT) obstruction, and presence of residual septal defects.

Following 6 months from hospital discharge, chest X-ray, echocardiography and mortality were also recorded.

\section{Results}

$37.1 \%$ of participants were younger than 6 months old and $62.9 \%$ were older than 6 months. Univariable analysis shows the only significant differences between the two groups was regarding ICU stay (3.6 day vs 5.04 day, $P$ value $=0.02)$ and postoperative complications $(53.8 \%$ vs $18.2, \mathrm{P}$ value $=0.01)$. Modified single patch technique was used in 39 cases $(55.7 \%)$, while in 31 cases $(44.3 \%)$, double-patch technique 
was used. Univariate analysis showed that surgical repair by modified single patch technique showed significant reduction in cross clamp time (mean $=47.6 \pm 9.227 \mathrm{~min}$ vs $73.55 \pm 21.087 \mathrm{~min}, \mathrm{P}$ value 0.001 ), shorter bypass time (mean $=71.13 \pm 13.507 \mathrm{~min}$ vs $99.19 \pm 27.092 \mathrm{~min}, \mathrm{P}$ value $=0.001$ ) and shorter duration of ICU stay (mean $=3.2 \pm 1.657$ days vs $5.3 \pm 2.761$ days, $P$ value $=0.01$ ) compared to double patch technique. Double patch technique was used more in patients with a large VSD component $(>8$ $\mathrm{mm})$ compared to modified single patch $(70.9 \%$ vs $23.4 \%$ of cases respectively, $P$ value $=0.001)$.

LAVV repair was performed by closure of cleft only by interrupted prolene sutures in 30 patients (42.9\%), while the remaining 40 patients $(57.1 \%)$ had additional posterior annuloplasty. Posterior annuloplasty compared to closure of cleft only resulted in significant reduction in the occurrence of post-operative valve regurgitation during the early period (LAVV regurgitation (LAVVR) grade $2+=7 \%$ vs $43 \%, P$ value $=$ 0.03 ) and at 6 months of follow up (LAVVR grade $2+=0 \%$ vs $35.4 \%$, P value $=0.01$ ), respectively.

Within our study sample, 64.3\% (45 patients) had Trisomy 21, whilst 35.7\% (25 patients) were NonTrisomy 21 participants. Univariate analysis showed that Trisomy 21 patients had significantly less incidence of postoperative moderate to severe LAVVR compared to Non-Trisomy 21 patients (LAVVR grade $2+=8.9 \%$ vs $24 \%$, P value $=0.005$, respectively) .

LAVV dysplasia is defined as the presence of anomalies including thickened leaflets, elongated chordae, lack of leaflet tissue, a double-orifice LAVV, excessive leaflet tissue and fusion of the commissures, and is traditionally diagnosed by echocardiography (10). In our study group, there was a strong association between incidence of LAVV dysplasia and Trisomy 21; (64\% vs 13.3\% in Trisomy 21 versus Non-Trisomy 21 patients, respectively $(P$ Value $=0.001)$ ).

On multivariate regression analysis, Trisomy 21 was associated with significantly less moderate to severe LAVV regurgitation compared to Non-Trisomy 21 patients $(P$ Value $=0.005)$. Mortality was comparable in Trisomy 21 versus Non-Trisomy 21 patients.

When compared with other variables, Posterior LAV Annuloplasty was found to be significantly protective against 6 months moderate to severe LAVVR and short term mortality. The addition of posterior annuloplasty to closure of common AV valve cleft was associated with significant reduction in the occurrence of post-operative LAVVR during 6 months of follow up and significant reduction in mortality $(P$ value $=0.001, P$ value $=0.002$ respectively .

Mortality was reported in $8.6 \%$ of patients ( 6 patients), 4 early within hospital stay ( 2 patients died from low COP and 2 from sepsis), whilst 2 died 6 months after discharge; 1 required readmission for a chest infection and died from sepsis, 1 died at home of unknown causes.

\section{Discussion}

The optimal age for surgical correction of CAVC defect has been addressed in several studies, most of which showed that successful repair at an early age was associated with competent AV valves at time of 
diagnosis, even in the presence of a cleft in the LAVV component $(18,19)$. Patients repaired at older ages were found to be more likely presenting with an incompetent $A V$ valve $(19,20)$. This may be due to chronically elevated QP/QS playing an important role in the onset of annular dilatation and secondary LAVV incompetence $(9,19)$. Early correction has been proposed to reduce the incidence of LAVV regurgitation (LAVVR) in the postoperative follow-up period $(21,22)$. This appears to be the most important factor affecting postoperative morbidity and mortality (10). Avoiding irreversible pulmonary hypertension, which may develop before the age of six months particularly in the presence of Trisomy 21 , is another reason to justify earlier repair $(10,21)$. Some studies advocate that the optimal timing for surgical intervention in patients with CAVC defect is when symptoms of congestive heart failure cannot be managed by medical therapy (23). Others believe that repair at the age of 4 to 6 months, before developing severe pulmonary hypertension, gives better results with no additional morbidities or mortality $(21,22,24)$.

In our study, we found no statistically significant difference between early surgical repair of CAVC defect in the first 6 months versus later repair, both regarding mortality and postoperative LAVVR. The only significant finding was in the ICU duration, which was longer in the younger age group. Stellin et al (10) performed a study assessing surgical treatment of CAVC defects in children before 3 months of age, with findings demonstrating that repair of CAVC under 3 months of age is the ideal approach to this malformation with a lower mortality rate at operation compared to older patients $(10,24)$. Logistic analysis showed that an operative age after 3 months is compared to an age before or equal to 3 months, an incremental risk factor for hospital mortality with an odds ratio of 4.8 (95\% confidence limit 1-23.5) $(P$ value $=0.05)(10)$. In the long term, freedom from reoperation for LAVV incompetence is higher when compared to children repaired at an older age (10).

Parikh et al(25) found no differences between the early ( $<90$ days) and late repair ( $>90$ days) age-groups at surgery for the outcomes of postoperative length of stay, heart block requiring pacemaker placement, rate of moderate or greater LAVVR, reoperation for LAVVR, and mortality(25).

Both modified single patch and double patch techniques can be used for the repair of CAVCD, with the former being superior in having shorter bypass time and cross clamp time, making it more popular( 11 , 26), although some surgeons believe that it may have associations with higher incidence of LVOT obstruction(27).

In our study, when compared to the double patch techniques, patients with a modified single patch had significantly shorter cross clamp time, bypass time and duration of ICU stay. Surgeons' preference in deciding which technique to use in the surgical repair is one important factor, some surgeons tend to use double patch technique with large VSD component, others favour the use of modified single patch technique in complete AVSD with large VSD (larger than $0.8 \mathrm{~mm}$ and up to $1.5 \mathrm{~mm}$ ), both, however, were found to have comparable results and outcomes(11,26, 27).

Addition of posterior annuloplasty to the common AV valve repair was suggested to prevent late reappearance of LAVVR(26). In this study, it showed a protective effect against moderate to severe LAVVR 
and short term mortality 6 months postoperatively, when compared to closure of cleft only. We believe that posterior annuloplasty maintains the valve competency and also restricts progressive dilatation of the LAVV, hence decreasing the need for reoperation. In a study performed by Myers et al, 219 patients were included to evaluate the impact of annuloplasty at CAVC repair on postoperative LAVV function(28). The cleft was closed completely in 192 patients (88\%). 65 patients had annuloplasty (39 commissural, 32 posterior). There were 5 early deaths (2.3\%). At discharge, 4 patients $(1.9 \%)$ had more than mild regurgitation and no patients had significant inflow gradients. During a follow-up of $2.7 \pm 2.1$ years, there were 6 late deaths $(2.8 \%)$ and 16 patients $(7.3 \%)$ required LAVV reoperation. Two of 65 patients $(3.1 \%)$ with annuloplasty required reoperation, compared to 14 of 148 without annuloplasty $(9.5 \%, p=0.16)$. In propensity matched analysis, annuloplasty was significantly protective of $\geq$ moderate LAVVR (OR $0.19, p$ $=0.008)$ and non-significantly of reoperation (OR 0.28, $p=0.099)(28)$.

There was a significant difference between Trisomy 21 patients and Non-Trisomy 21 patients regarding postoperative, early and 6 months follow-up LAVVR. Additionally, there was a significantly higher incidence of common AVV dysplasia and malformation in Non-Trisomy 21 patients when compared to Trisomy 21 patients. The significant difference between postoperative LAVVR between the two groups may be due to the difference in AV valve dysplasia and malformations, which makes surgical repair of LAVV and maintenance of valve competency much more difficult, regardless of surgical technique used.

Formigari et al. found there were no significant differences in survival between Trisomy 21 and NonTrisomy 21 patients with overall mortality being 7.7\% (29). Survival was $94 \%$ among patients with Trisomy 21 versus $86 \%$ of Non-Trisomy 21 patients $(p=0.12)$. When comparing incidence of reoperation due to postoperative LAVVR or LVOT obstruction, a higher prevalence of reoperation in CAVC was found in Non-Trisomy 21 patients ( $81.4 \%$ vs $94.6 \%, p=0.04$ ), due to the higher prevalence of anomalies of the mitral valve (4.9\% vs $1.8 \%, \mathrm{p} 0.03)$, as well as higher LVOT prevalence ( $7.3 \%$ vs $0 \%, \mathrm{p} 0.01)(29)$.

Kaza et al found some preoperative and intraoperative differences between the two groups but of no significance, and outcomes were found to be similar(30). Hospital courses were also similar with the exception of a number of in-hospital complications (higher in the Non-Trisomy 21 group). Mortality at 6 months was identical at 4\%, but there was a trend towards more reoperations in the first 6 months in the Non-Trisomy 21 group (13\% vs. $2 \%, p=0.06)(30)$. Moderate or severe LAVVR was more likely in the NonTrisomy 21 group prior to AVSD surgery, however, the prevalence of LAVVR did not differ at 1 month and 6 months post-surgery(30).

We can conclude that Trisomy 21 is no longer a risk factor for adverse outcomes regarding postoperative LAVVR and mortality, so early intervention in the first 6 months in patients with Trisomy 21 is advocated to provide better results when compared to Non-Trisomy 21 patients, and gives comparable results compared to delaying surgery after 6 months.

\section{STUDY LIMITATIONS}


In this study, we ensured that our methodology was coherent. We optimised our selection criteria to make our findings generalisable to a wider patient population. However, this study still has a number of limitations, namely a limited study sample and a short follow-up. Other limitations, owing to the retrospective nature of the study, included possible unaccounted confounders such as sex, ethnicity and the presence of comorbidities, heterogeneity of operations as well as information bias during data collection.

\section{Conclusion}

In our experience, early intervention by surgical repair in CAVC defect patients during the first 4 to 6 months had good outcomes and comparable results to delayed surgery at older age. Trisomy 21 was not found to be a risk factor for early intervention and had better outcomes regarding postoperative LAVVR compared to Non-Trisomy 21 patients.

Double patch technique was performed more often in patients with a large VSD component, however, use of modified single patch technique in large VSD gave comparable results, shorter bypass and cross clamp time when compared with double patch technique.

No significant difference was found regarding mortality and LAVVR between both surgical techniques used. Repair of common AV valve by cleft closure with posterior LAV annuloplasty showed better results with a significant decrease in postoperative LAVVR and short term mortality in comparison with closure of cleft only.

\section{List Of Abbreviations}

Atrial septal defect: ASD

Atrioventricular: AV

Atrioventricular valves: AVV

Complete Atrio-Ventricular Canal Defect: CAVC

Left atrioventricular valve: LAVV

Left atrioventricular valve regurgitation: LAVVR

Left ventricular outflow tract: LVOT

Right atrioventricular valve: RAVV

Ventricular septal defect: VSD

\section{Declarations}


Funding: None

Conflicts of interest/Competing interests: None

Availability of data and material: N/A

Code availability: N/A

Authors' contributions: All authors have contributed to the study conception and design

Ethics approval: This study has been approved by the Institutional Review Boards of the University of AinShams.

Consent to participate: N/A

Consent for publication: N/A

\section{References}

1. Rastelli G, Kirklin JW, Titus JL. Anatomic observations on complete form of persistent common atrioventricular canal with special reference to atrioventricular valves - PubMed. Mayo Clinic Procedures . 1996;41(5): 296-308. Available from: https://pubmed.ncbi.nlm.nih.gov/5932615/

2. Calabrò R, Limongelli G. Complete atrioventricular canal. Orphanet Journal of Rare Diseases. BioMed Central; 2006. p. 8. Available from: doi:10.1186/1750-1172-1-8

3. Berger TJ, Kirklin JW, Blackstone EH, Pacifico AD, Kouchoukos NT. Primary repair of complete atrioventricular canal in patients less than 2 years old. The American Journal of Cardiology. Am J Cardiol; 1978;41(5): 906-913. Available from: doi:10.1016/0002-9149(78)90732-4

4. Hanley FL, Fenton KN, Jonas RA, Mayer JE, Cook NR, Wernovsky G, et al. Surgical repair of complete atrioventricular canal defects in infancy: Twenty-year trends. Journal of Thoracic and Cardiovascular Surgery. Mosby; 1993;106(3): 387-397. Available from: doi:10.1016/s0022-5223(19)34070-x

5. Crawford FA, Stroud MR. Surgical repair of complete atrioventricular septal defect. Annals of Thoracic Surgery. Elsevier; 2001;72(5): 1621-1629. Available from: doi:10.1016/S00034975(01)03170-8

6. Vida VL, Tessari C, Castaldi B, Padalino MA, Milanesi O, Gregori D, et al. Early Correction of Common Atrioventricular Septal Defects: A Single-Center 20-Year Experience. Annals of Thoracic Surgery. Elsevier USA; 2016;102(6): 2044-2051. Available from: doi:10.1016/j.athoracsur.2016.09.020

7. st. Louis JD, Jodhka U, Jacobs JP, He X, Hill KD, Pasquali SK, et al. Contemporary outcomes of complete atrioventricular septal defect repair: Analysis of the Society of Thoracic Surgeons Congenital Heart Surgery Database. Journal of Thoracic and Cardiovascular Surgery. Mosby Inc.; 2014;148(6): 2526-2531. Available from: doi:10.1016/j.jtcvs.2014.05.095 
8. Ginde S, Lam J, Hill GD, Cohen S, Woods RK, Mitchell ME, et al. Long-term outcomes after surgical repair of complete atrioventricular septal defect. Journal of Thoracic and Cardiovascular Surgery. Mosby Inc.; 2015;150(2): 369-374. Available from: doi:10.1016/j.jtcvs.2015.05.011

9. Michielon G, Stellin G, Rizzoli G, Casarotto DC. Repair of complete common atrioventricular canal defects in patients younger than four months of age. Circulation. 1997;96(9 SUPPL.): II-316. Available from: http://intl-circ.ahajournals.org/cgi/content/full/96/9/II

10. Stellin G. Surgical treatment of complete A-V canal defects in children before 3 months of age. European Journal of Cardio-Thoracic Surgery. Oxford Academic; 2003;23(2): 187-193. Available from: doi:10.1016/S1010-7940(02)00760-1

11. Nicholson IA, Nunn GR, Sholler GF, Hawker RE, Cooper SG, Lau KC, et al. Simplified single patch technique for the repair of atrioventricular septal defect. Journal of Thoracic and Cardiovascular Surgery. Mosby Inc.; 1999;118(4): 642-647. Available from: doi:10.1016/S0022-5223(99)70009-7

12. Wilcox BR, Jones DR, Frantz EG, Brink LW, Henry GW, Mill MR, et al. Anatomically sound, simplified approach to repair of "complete" atrioventricular septal defect. Annals of Thoracic Surgery. Elsevier; 1997;64(2): 487-494. Available from: doi:10.1016/S0003-4975(97)00566-3

13. Jonas RA, Mora B. Individualized Approach to Repair of Complete Atrioventricular Canal: Selective Use of the Traditional Single-Patch Technique Versus the Australian Technique. World Journal for Pediatric and Congenital Heart Surgery. World J Pediatr Congenit Heart Surg; 2010;1(1): 78-86. Available from: doi:10.1177/2150135110361510

14. Mavroudis C, Backer CL. The two-patch technique for complete atrioventricular canal. Seminars in thoracic and cardiovascular surgery. 1997;9(1): 35-43. Available from: https://europepmc.org/article/med/9109223

15. Maloney JV., Marable SA, Mudler DG. The surgical treatment of common atrioventricular canal. The Journal of thoracic and cardiovascular surgery. Mosby; 1962;43(1): 84-96. Available from: doi:10.1016/s0022-5223(20)31630-5

16. Jeong IS, Lee CH, Lee C, Lim HG, Kim IS, Youn HC, et al. Institutional report - Congenital surgical outcomes of the modified single-patch technique in complete atrioventricular septal defect. Interactive Cardiovascular and Thoracic Surgery. Interact Cardiovasc Thorac Surg; 2009. p. 435-437. Available from: doi:10.1510/icvts.2008.192872

17. Nunn GR. Atrioventricular Canal: Modified Single Patch Technique. Pediatric Cardiac Surgery Annual. W.B. Saunders; 2007;10(1): 28-31. Available from: doi:10.1053/j.pcsu.2007.01.009

18. Yasui $H$, Nakamura Y, Kado H, Yonenaga K, Shiokawa Y, Fusazaki N, et al. Primary repair for complete atrioventricular canal: Recommendation for early primary repair. Journal of Cardiovascular Surgery. 1990. p. 498-504. Available from: https://europepmc.org/article/med/2211806

19. Mavroudis C, Weinstein G, Turley K, Ebert PA. Surgical management of complete atrioventricular canal. Journal of Thoracic and Cardiovascular Surgery. Mosby; 1982;83(5): 670-679. Available from: doi:10.1016/s0022-5223(19)37205-8 
20. Günther T, Mazzitelli D, Haehnel CJ, Holper K, Sebening F, Meisner H. Long-term results after repair of complete atrioventricular septal defects: Analysis of risk factors. Annals of Thoracic Surgery. Elsevier; 1998;65(3): 754-760. Available from: doi:10.1016/S0003-4975(98)00028-9

21. Suzuki T, Bove EL, Devaney EJ, Ishizaka T, Goldberg CS, Hirsch JC, et al. Results of Definitive Repair of Complete Atrioventricular Septal Defect in Neonates and Infants. Annals of Thoracic Surgery. Elsevier; 2008;86(2): 596-602. Available from: doi:10.1016/j.athoracsur.2008.02.032

22. Atz AM, Hawkins JA, Lu M, Cohen MS, Colan SD, Jaggers J, et al. Surgical management of complete atrioventricular septal defect: Associations with surgical technique, age, and trisomy 21. Journal of Thoracic and Cardiovascular Surgery. NIH Public Access; 2011;141(6): 1371-1379. Available from: doi:10.1016/j.jtcvs.2010.08.093

23. Reddy VM, McElhinney DB, Brook MM, Parry AJ, Hanley FL, Alexander JA, et al. Atrioventricular valve function after single patch repair of complete atrioventricular septal defect in infancy: How early should repair be attempted? Journal of Thoracic and Cardiovascular Surgery. Mosby Inc.; 1998;115(5): 1032-1040. Available from: doi:10.1016/S0022-5223(98)70402-7

24. Singh RR, Warren PS, Reece TB, Ellman P, Peeler BB, Kron IL. Early Repair of Complete Atrioventricular Septal Defect is Safe and Effective. Annals of Thoracic Surgery. Ann Thorac Surg; 2006;82(5): 15981602. Available from: doi:10.1016/j.athoracsur.2006.05.102

25. Parikh KN, Shah NC, Myers JL, Kunselman AR, Clark JB. Complete Atrioventricular Canal Defect: Influence of Timing of Repair on Intermediate Outcomes. World Journal for Pediatric and Congenital Heart Surgery. SAGE Publications; 2017;8(3): 361-366. Available from: doi:10.1177/2150135117696492

26. Fong LS, Winlaw DS, Orr Y. Is the modified single-patch repair superior to the double-patch repair of complete atrioventricular septal defects? Interactive CardioVascular and Thoracic Surgery. Oxford University Press; 2019;28(3): 427-431. Available from: doi:10.1093/icvts/ivy261

27. Nunn GR. Atrioventricular Canal: Modified Single Patch Technique. Pediatric Cardiac Surgery Annual. W.B. Saunders; 2007;10(1): 28-31. Available from: doi:10.1053/j.pcsu.2007.01.009

28. Myers PO, del Nido P, Marx G, Emani S, Pigula F, Mayer J, et al. Annuloplasty At Atrioventricular Canal Repair Improves Late Left Atrioventricular Valve Function. Journal of the American College of Cardiology. Elsevier BV; 2012;59(13): E776. Available from: doi:10.1016/s0735-1097(12)60777-3

29. Formigari R, di Donato RM, Gargiulo G, di Carlo D, Feltri C, Picchio FM, et al. Better surgical prognosis for patients with complete atrioventricular septal defect and Down's syndrome. Annals of Thoracic Surgery. Ann Thorac Surg; 2004;78(2): 666-672. Available from: doi:10.1016/j.athoracsur.2003.12.021

30. Kaza AK, Colan SD, Jaggers J, Lu M, Atz AM, Sleeper LA, et al. Surgical interventions for atrioventricular septal defect subtypes: The pediatric heart network experience. Annals of Thoracic Surgery. Ann Thorac Surg; 2011;92(4): 1468-1475. Available from: doi:10.1016/j.athoracsur.2011.04.109 


\section{Tables}

Table 1

Multivariate regression analysis for mortality within the cohort operated on.

\begin{tabular}{|llllll|}
\hline & Sum of Squares & Df & Mean Square & F & P value \\
\hline Regression & 1.896 & 4 & .474 & 3.353 & $.015^{\mathrm{b}}$ \\
\hline Residual & 9.189 & 65 & .141 & & \\
\hline Total & 11.086 & 69 & & & \\
\hline
\end{tabular}

Table 2

Coefficients required for Table 1 which show multivariate regression analysis for mortality within the cohort, alongside $\mathrm{P}$ values for compared fields. *Reference $\leq 16 \mathrm{~ms}$ group,

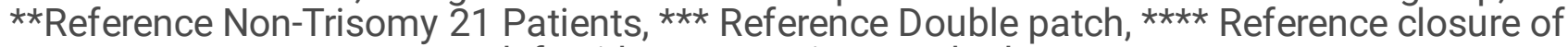
cleft without posterior annuloplasty.

\begin{tabular}{|c|c|c|c|c|}
\hline & \multicolumn{2}{|c|}{ Unstandardized Coefficients } & \multirow[t]{2}{*}{$\mathrm{t}$} & \multirow[t]{2}{*}{$P$ value } \\
\hline & B & Std. Error & & \\
\hline Age (> 6 months)* & -.159 & .099 & -1.603 & .114 \\
\hline Trisomy $21^{\star \star}$ & -.040 & .096 & -.417 & .678 \\
\hline Surgical Technique ${ }^{\star \star \star(M o d i f i e d ~ s i n g l e) ~}$ & .099 & .101 & .975 & .333 \\
\hline LAV posterior ${ }^{\star \star \star \star}$ Annuloplasty repair & -.324 & .099 & -3.273 & .002 \\
\hline
\end{tabular}

Table 3

Multivariate regression analysis of $6 \mathrm{~m}$ LAVVR present postoperatively in the cohort.

\begin{tabular}{|llllll|}
\hline & Sum of Squares & Df & Mean Square & F & P value \\
\hline Regression & 14.269 & 4 & 3.567 & 7.162 & .001. \\
\hline Residual & 32.374 & 65 & .498 & & \\
\hline Total & 46.643 & 69 & & & \\
\hline
\end{tabular}


Table 4

Coefficients ${ }^{a}$ required for Table 3 which show multivariate regression analysis of $6 \mathrm{~mm}$ LAVVR present postoperatively in the cohort, alongside $\mathrm{p}$ values of compared fields. *Reference $\leq 1$

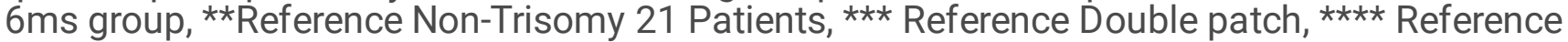
closure of cleft without posterior annuloplasty.

\begin{tabular}{|c|c|c|c|c|}
\hline & \multicolumn{2}{|c|}{ Unstandardized Coefficients } & \multirow[t]{2}{*}{$\mathrm{T}$} & \multirow[t]{2}{*}{$P$ value } \\
\hline & B & Std. Error & & \\
\hline $\operatorname{Age}(>6$ months)* & -.105 & .186 & -.565 & .574 \\
\hline Trisomy $21^{\star \star}$ & -.523 & .181 & -2.892 & .005 \\
\hline Surgical Technique ${ }^{\star \star \star(m o d i f i e d ~ s i n g l e) ~}$ & .167 & .190 & .877 & .384 \\
\hline 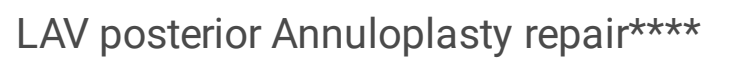 & -.730 & .186 & -3.926 & .001 \\
\hline
\end{tabular}

